\title{
Design and analysis of flat joint connection of double wishbone suspension A arm
}

\author{
Mr. Mahesh H. More ${ }^{1}$, Dr. Shekhar Yadgiri Gajjal ${ }^{2}$ \\ ${ }^{I}$ (Mechanical design, N.B.N.Sinhgad school of Engineering affiliated to Savitribai Phule Pune University, India) \\ ${ }^{2}$ (H.O.D. (M.E.) Mechanical design, N.B.N.Sinhgad school of Engineering affiliated to Savitribai Phule Pune
}

University, India)

\begin{abstract}
Work involves new product development into A arm component for automotive development. Frame round cage roll is having sustaining issue so to resolve the issue here A arm mounting get changed and instead of round bar weldment flat frame design incorporated. So to make stability in off highway vehicle as strength point of view this sustaining project executed. It's a redesigning work with A arm while installation may having difficulties so to make feasible and safe installation, A arm structure is changed with its joint of assembly instead of pipe joint. We developed here U joint with bolting on flat frame. CAE comparison is taken to make validation, boundary conditions considered here are standard input and referred by standard similar configurations.
\end{abstract}

Keywords: A-arm, CAE, Flat Frame, U-joint, Validation.

\section{Introduction}

\subsection{Problem Identification and Overcomes}

Frame round cage roll is having sustaining issue so to resolve the issue here A arm mounting get changed and instead of round bar weldment flat frame design incorporated. Presently cage is in tube weldment structure as the roll cage is having limitation on crushing loads sustaining behaviour, now we need to change frame handling stability of roll cage with holding all load on it and assembling roll cage on flat flame cut frame.

So now mounting of all the subordinates and subassemblies will get change and modification and new designing is existing for A arm suspension assembly. So to replace joints between roll cage frame and A arm this modifying and sustaining work is executed and this is a need of strengthening the product in standardized process.

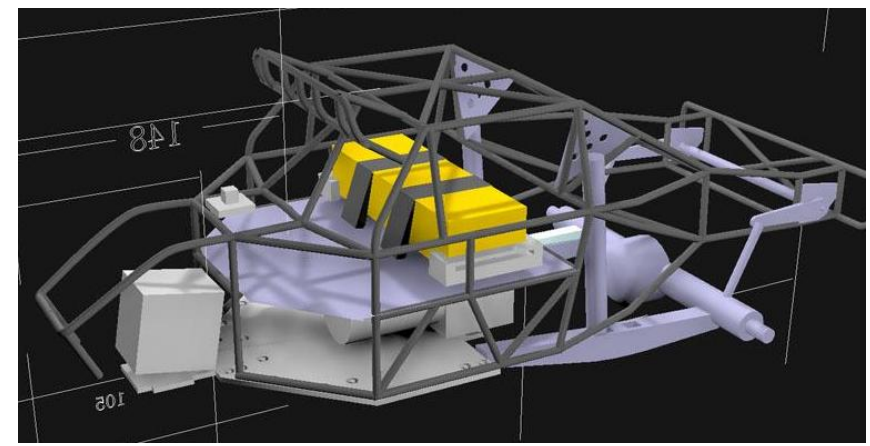

Fig. 1

\subsection{Literature Survey}

Asst. Prof. N.Vivekanandan ${ }^{[1]}$ conducted study on Double Wishbone suspension system. Double Wishbone Suspension System consists of double lateral controlling arms (upper arm and lower arm) usually of dissimilar length along with a over spring and shock absorber assembly. It is known as front suspension mostly installed in rear wheel power drive vehicles. Design of double wishbone suspension system taking with formulation of spring plays a very effective role in creating the stability of the vehicle body. This type of system increasing negative camber obtaining all the straight way to full jounce travel unlike Macpherson Strut. They also allow simple adjustment of wheel assembly like camber. Double wishbone suspension assembly has super dynamic characteristics as well as load-handling power. Design of wishbones is the starting stage to design and formulate the suspension system. The material is obtaining using Pugh's Concept of Optimization. Basically on the properties of the selected body material, the allowable stress is calculated using standard sheer stress theory of failure occurs. The body roll-centre is determined to find the tie-rod simple length. The designed 
Wishbones are modelled using soft tool and then validate using Ansys software to find the maximum stress and maximum deformation in the body wishbone.

Material Selection of Wishbone ${ }^{[1]}$. This becomes the most primary need for design and producing. The capability of the material should be well controlled to withstand all the loads acting on it in all conditions. The material selection also depends on number of parameters such as carbon content, material properties, availability and the most important parameter is the costing. In starting 3 materials are selected based on their availability in the nearer market AISI 1018, AISI 1040 and AISI 4130. By using Pugh's concept of engineering optimization, we have chosen material grade AISI 1040 for the wishbones body.

Eshaan Ayyar,Isacc de Souza, Aditya Parvin, Sanket Tambe, Aqleem Siddiqui and Nitin Gurav conducted study on suspension system for ATV ${ }^{[2]}$. REAR WISHBONE. Rear wishbone in starting, the A-arm was installed for the back suspension. While the vehicle body takes a turn, due to the horizontal loads acting on the links attached of the wishbones and the knuckle joint and due to avoiding less steering on the rear wheels, there can be toe-in and toe-out of the wheels. This may lead to unbalanced steering and may result in unbalance body. Excess toe-in can impact over steer while moment leading to loss of control. Excess toe-out can cause with steering while turning. To avoid any toeing, the A-arm shape is converted into H- shaped arm (as shown in below). Thus the vertical pin knuckle-wishbone assembly structure is replaced into horizontal pin attachment. This avoids formation of an axis and due to which the chances of toeing of the wheels with body. This gives full proofed balancing, align and steering. It also expands the ride stability.

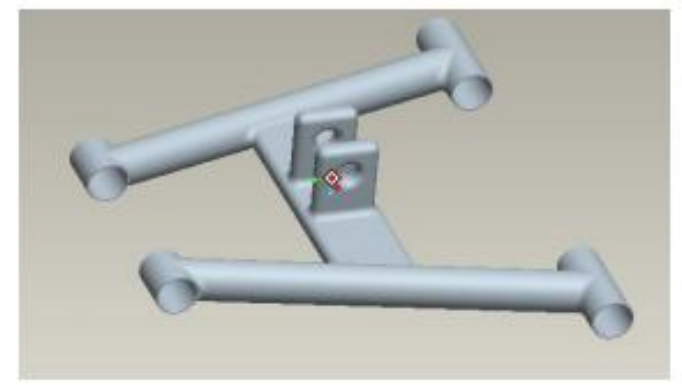

Fig. 2 Rear Wishbone ${ }^{[2]}$

\subsection{Objective}

1.3.1 To Design customized A arm for flat joint of roll cage.

1.3.2 To verify sustainability with joint.

1.3.3 To standardize wishbone A arm particularly on flat joint assembly.

\subsection{Testing Using Software Ansys Workbench}

Testing the assembly structure using software tools initially some basic load distribution calculations are done to get the values of force acting on each of the member arms. Here the upper and lower wishbones are tested on ANSYS for determining rigidity and safety of the arms. A force of $3 \mathrm{G}$ Newton was applied to the base of tyre considering weight transfer during braking and jounce/rebound. This force was transmitted to the upper and lower links and is calculated by simple vector mechanics. The software is used to calculate the maximum deformation and the maximum equivalent stress induced in the arms. The behaviour of the arms is discussed below ${ }^{[3]}$

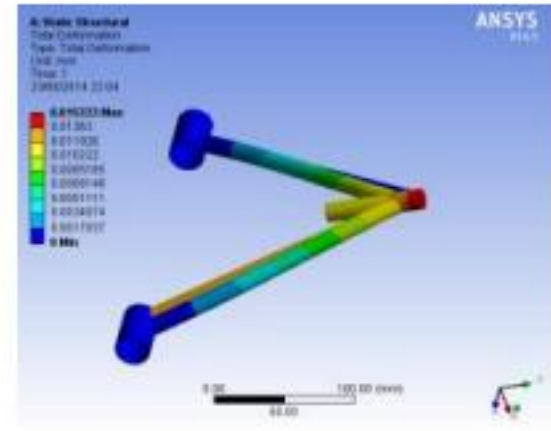

Fig.3 A arm total deformation ${ }^{[3]}$

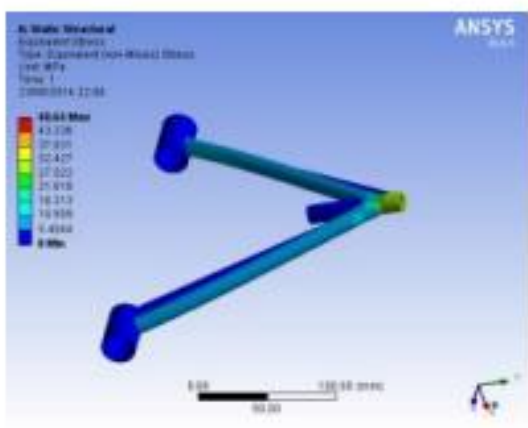

Fig 4. A arm equivalent stress ${ }^{[3]}$ 


\section{Boundary conditions:}

\section{Design Consideration}

Considering rough conceptual stage

Stress Calculation For ductile materials, allowable stress is obtained by the following relationship

Assume factor of safety, fs $=1.2$

$$
\sigma=s_{y t} / f s
$$

(as is a ductile material)

$$
\sigma=415 / 1.2=345.83 \mathrm{MPa}
$$

It is the Amount of allowable stress in the wishbones structure. The designed wishbone is safe when the Opting stress is under the allowable stress. The allowable stress is obtained using Ansys analysis CAE tool.

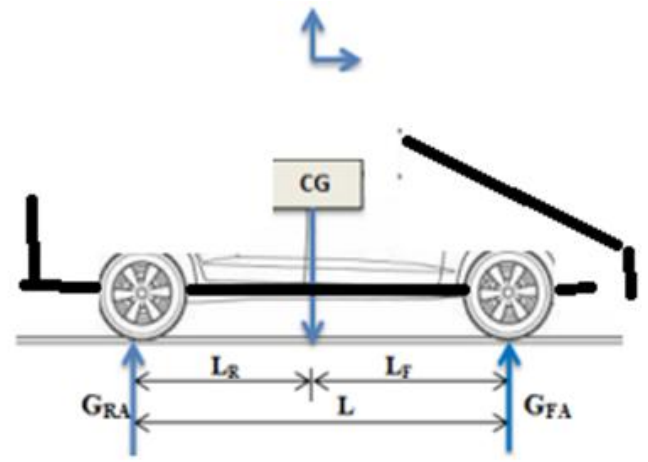

Fig.5 Under static loading condition

Consider the vehicle shown in Figure.

The total weight of off highway motor acting at its centre of gravity is:

$$
\mathrm{G}=\mathrm{mXg}
$$

The loads coming on front side and rear side axles are out by using the equilibrium Equations;

$$
\begin{aligned}
& G_{F A}=G\left(L_{R} / L\right) \\
& G_{R A}=G\left(L_{F} / L\right)
\end{aligned}
$$

Static conditional load on single wheel of the front axle is:

$$
\begin{aligned}
G_{F A w} & =G_{F A} / 2 \\
G_{R A w} & =G_{R A} / 2
\end{aligned}
$$

By using above formulation for the object (vehicle) of total standard mass $2300 \mathrm{~kg}$ and at constant speed we assumed $30 \mathrm{~km} / \mathrm{hr}$., we can determine condition on one wheel of the object so far it will be the weight on lower suspension arm of front side wheel.

If $\mathrm{m}=2300 \mathrm{~kg}$,

From Equation no. (1)

$$
\begin{aligned}
& \mathrm{G}=2300 \times 9.81 \mathrm{~N} \\
& \mathrm{G}=22563 \mathrm{~N}
\end{aligned}
$$

The loads on front axle can be calculate using equation no. (2)

$$
\begin{aligned}
G_{F A} & =22563 \times(1285 / 2900) \\
G_{F A} & =9997.7431 \mathrm{~N}
\end{aligned}
$$

Load on the rear axle is by using equation (3)

$$
\begin{aligned}
G_{R A} & =22563 \mathrm{x}(1615 / 2900) \\
G_{R A} & =12565.2569 \mathrm{~N}
\end{aligned}
$$

Load on the front wheel and rear wheel can be found by using equation no. (4) and (5)

Similarly,

$$
G_{F A w}=9997.7431 / 2 \quad G_{F A w}=4998.8715 \mathrm{~N}
$$

$$
G_{R A w}=6282.6284 \mathrm{~N}
$$

From result of boundary loads for standard required vehicle we got load on the front side wheel $4997.8715 \mathrm{~N}$ and for rear wheel it is $6282.6284 \mathrm{~N}$. 
We are focusing on A arm design so wheel consideration is only our zone for analysis we consider forces on lower suspension arm $4997 \mathrm{~N}$ which can be considered equal to $5000 \mathrm{~N}$. So, for our further formulation we consider load of $5000 \mathrm{~N}$ acting on front lower A arm.

So we can now develop the 3 model of Arm suspension and applying load.

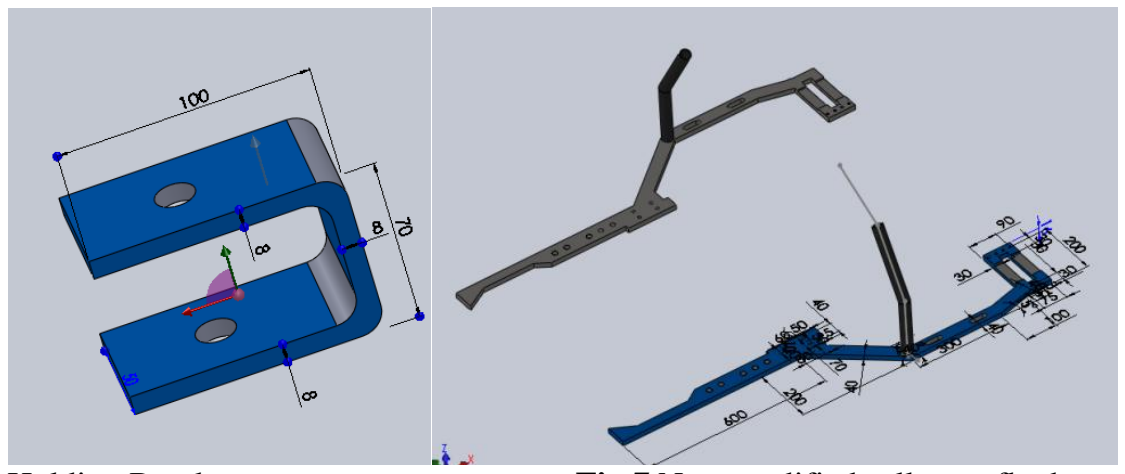

Fig. 6 Holding Bracket

Fig.7 New modified roll cage flat base frame

Frame for roll cage weldment on which A arm mounting is to be made feasible. This plate is $16 \mathrm{~mm}$ thicken and made from flame cutting from raw material of big size sheet. This part is in one piece formation applying flame cutting and smooth corners at every edge.

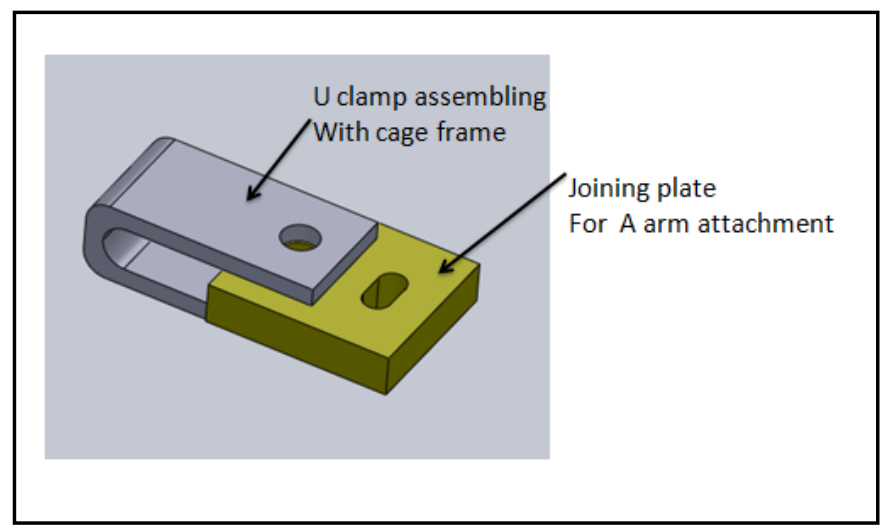

Fig. 8 Subassembly of U clamp

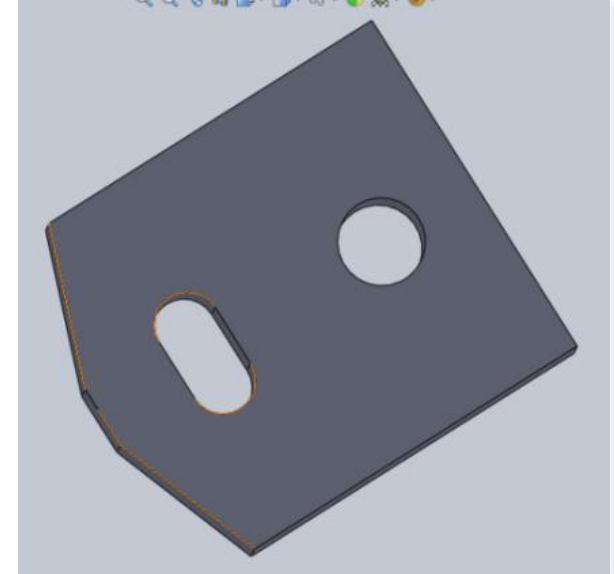

Fig. 9. Flat flange

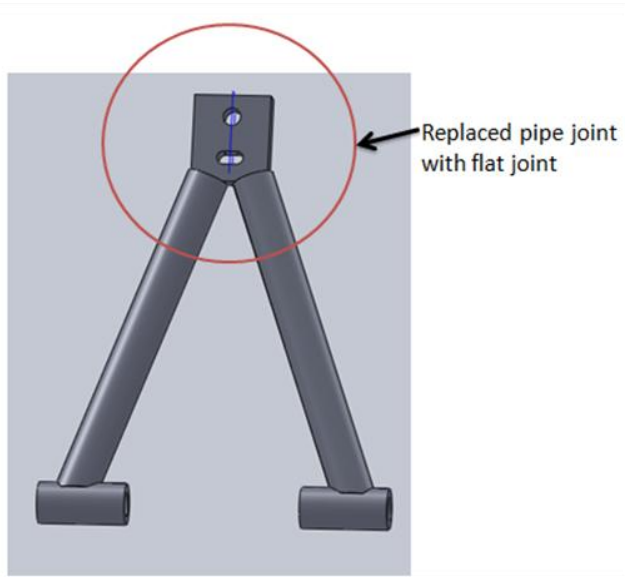

Fig. 10. A shaped weldment formation

Now A shaped clamp is taking all loads on it so let's define the configure values to it.

Performance under working conditions of $\mathrm{L}$ shape lower part of U clamp as we knows that all the loads will exerted on lower L shape vertically but still we designed U clamp because of fastening and holding purpose of wishbone A arm. 
Loads we are considering per unit area

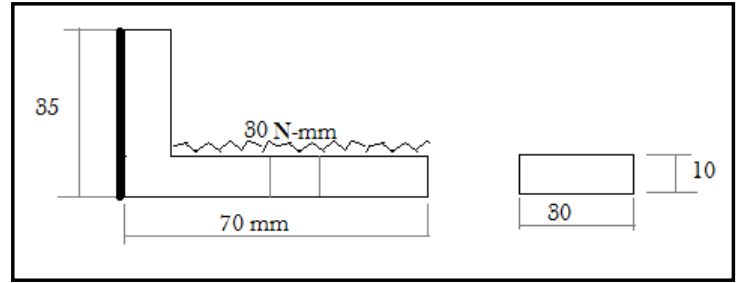

Fig. 11

As seen from the Bending moment Diagram,

Maximum bending moment $\mathrm{M}=73500 \mathrm{~N}-\mathrm{mm}$

Moment of inertia, $\mathrm{I}=\mathrm{bt}^{3} / 12$

$\mathrm{I}=\left(30 \times 10^{3}\right) / 12$

$\mathrm{I}=2500 \mathrm{~mm}^{4}$

The bending stress in the member is calculated as

$$
\begin{gathered}
\frac{M}{I}=\frac{\sigma}{y} \\
\frac{73500}{2500}=\frac{\sigma}{4}
\end{gathered}
$$

Bending Stress, $\sigma=147.00 \mathrm{~N} / \mathrm{mm}^{2}$

$$
\delta=\frac{w l^{4}}{8 E I}
$$

$$
\begin{aligned}
\delta & =\frac{30 \times 70^{4}}{8 \times 200 \times 10^{3} \times 2500} \\
\delta & =0.18007 \mathrm{~mm}
\end{aligned}
$$

Hence,

Maximum bending stress developed in the member $=147.00 \mathrm{~N} / \mathrm{mm}^{2}$

And Maximum deflection of the member $=0.18007 \mathrm{~mm}$

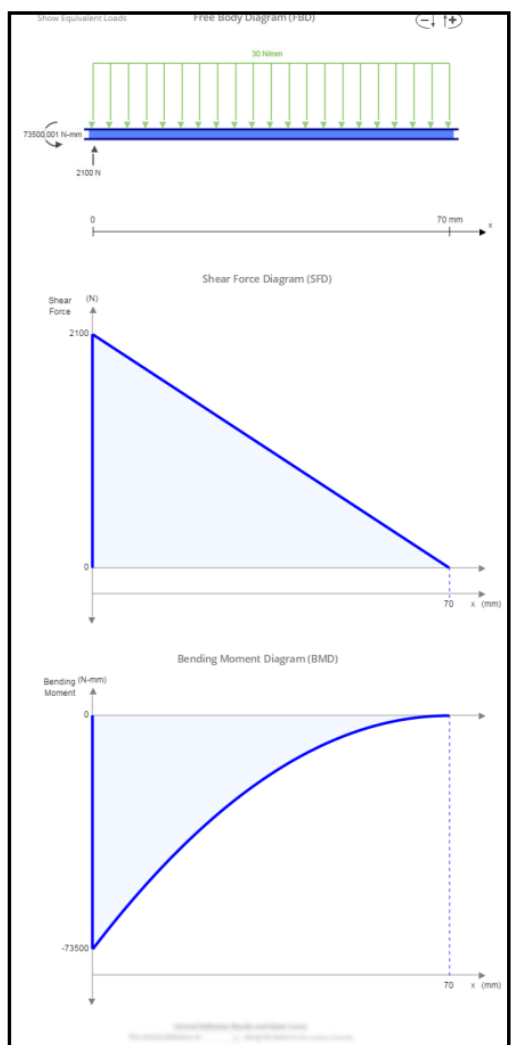

Fig. 12. Bending Moment diagram 


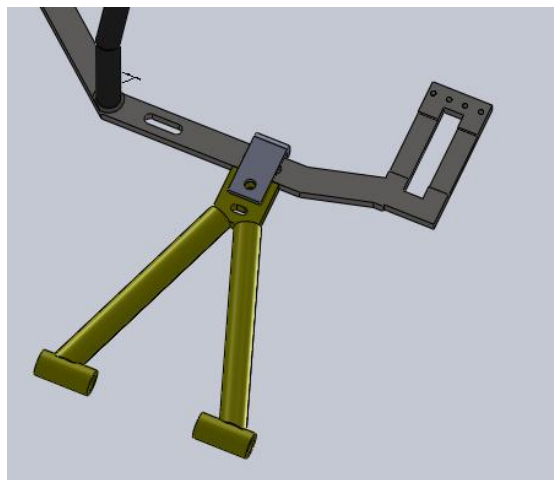

Fig. 13. A arm assembly installed on flat frame

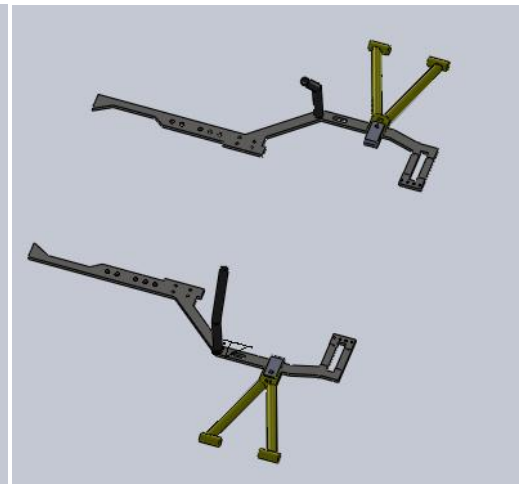

Fig. 14. Both side installation feasibility

\subsection{Structural behaviour of u clamp}

\section{CAE Validation}

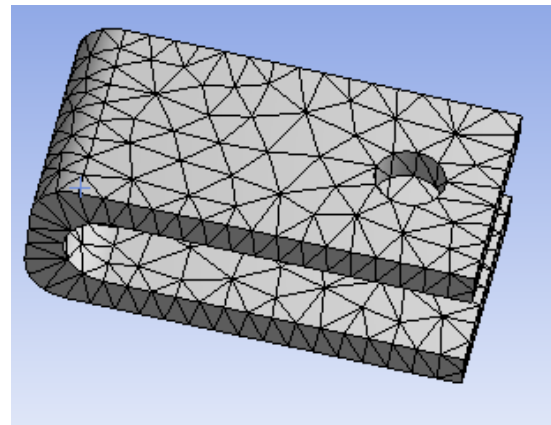

Fig.15 Meshed model

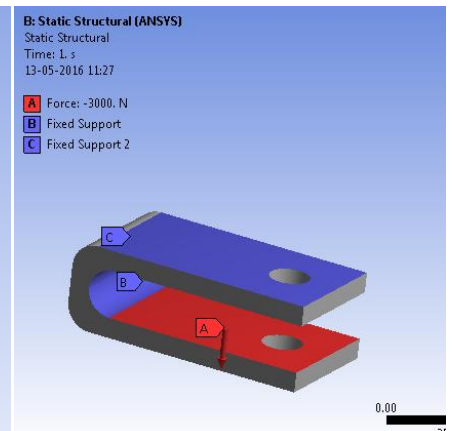

Fig.16. Boundary conditions applied

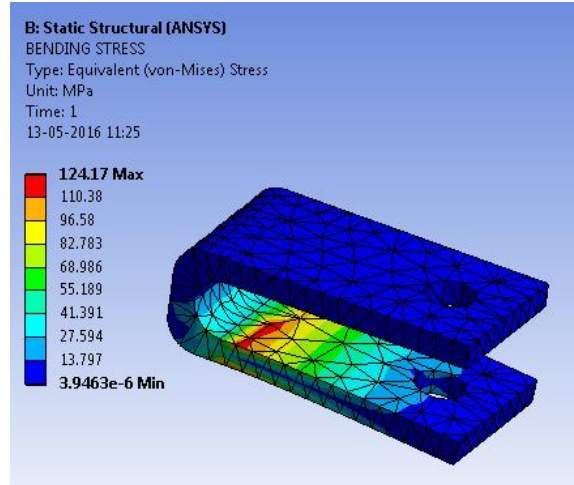

Fig. 17. Bending stress STRESS VALUE $=124.17 \mathrm{Mpa}$

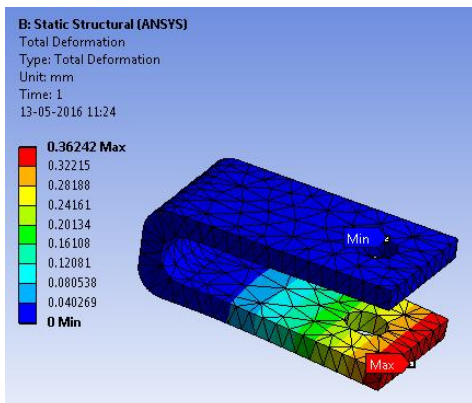

Fig. 19. Deflection result Deflection $=0.36 \mathrm{~mm}$

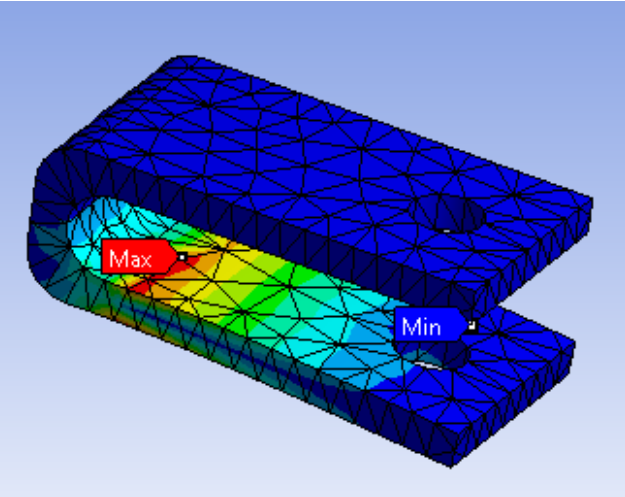

Fig.18. Bending stress zone

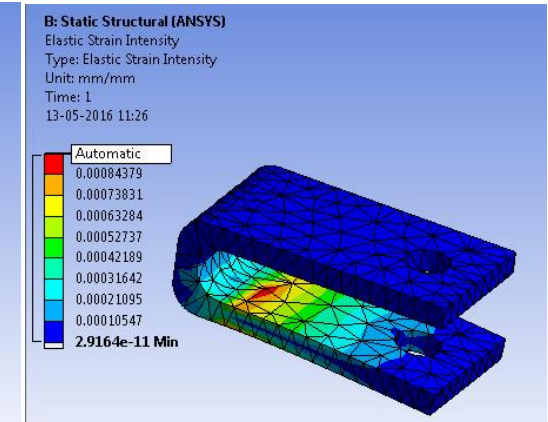

Fig.20. Range showing strain value 


\subsection{Overall assembly behaviour}

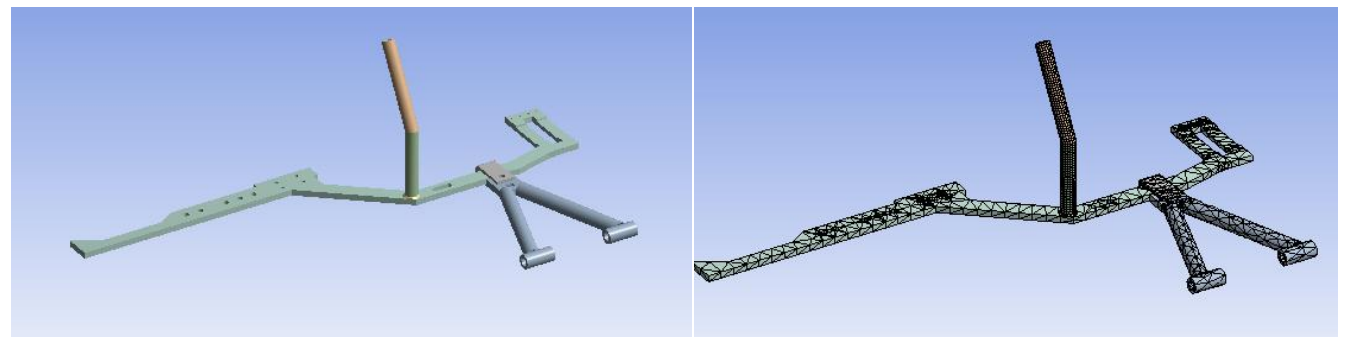

Fig. 21. Geometry Imported

Fig. 22. Meshed Assembly

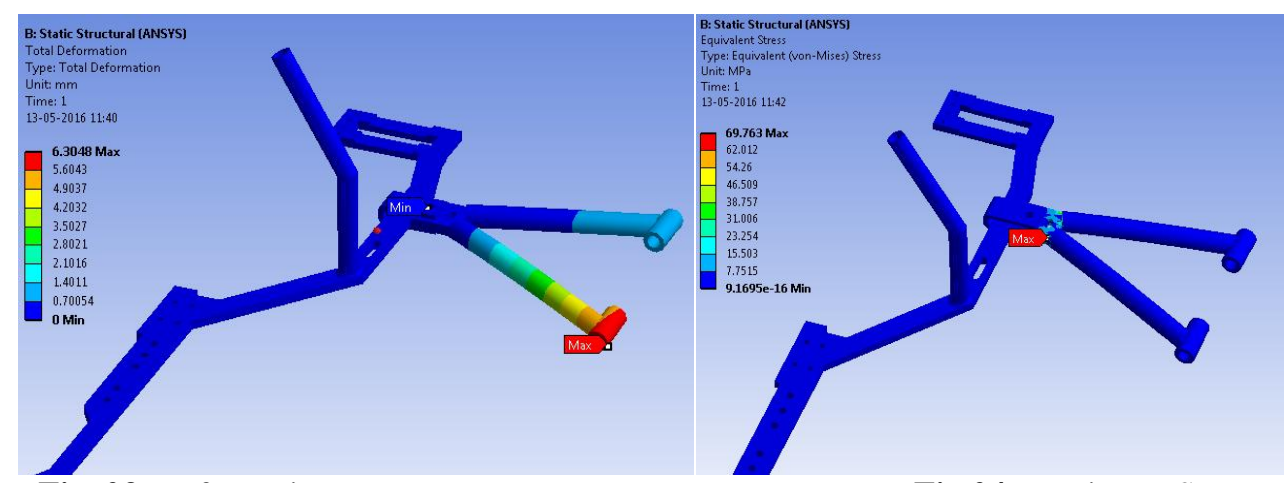

Fig. 23. Deformation Test

Fig.24. Maximum Stress

From above, Deformation $6.3 \mathrm{~mm}$ and Maximum Stress is $69.73 \mathrm{Mpa}$

It's found below yield strength of the material

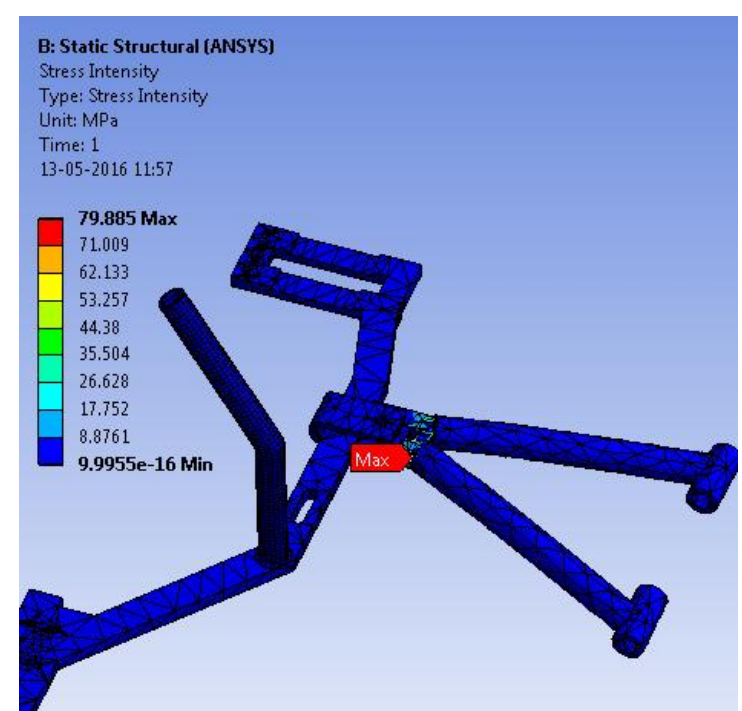

Fig. 25. Stress Intensity Range

\section{Result}

From output data

\begin{tabular}{|c|c|c|}
\hline Parameters & Design & CAE output \\
\hline Max stress & $147 \mathrm{Mpa}$ & $124.3 \mathrm{Mpa}$ \\
\hline Deflection & $0.18 \mathrm{~mm}$ & $0.36 \mathrm{~mm}$ \\
\hline
\end{tabular}

In assembly 79.885 Mpa stress reaches at maximum point, it can be considered as safe side working condition.

\section{Conclusion}

The behavior under load performing strategy of the new designed joint with A-arm modification will effectively work in maximum loaded boundary conditions from the results came out. It has been seen that this 
kind of A arm can be standardized for roll cage flat joint. So in All Terrain Vehicle (ATV) this can be used if flat joint is present. Still somewhere improvement can be done where the assembly process will be highlighted with new techniques of assembling A arm as compared to conventional A arm. Extra machining cost is taking effect but no option, we have changed this design due to base frame changing occurs.

\section{References}

[1] Asst.Prof.N.Vivekanandan, Abhilash Gunaki,Chinmaya Acharya, Savio Gilbert and Rushikesh Bodke, “ Design, Analysis and Simulation of Double Wishbone Suspension System", IPASJ International Journal of Mechanical Engineering (IIJME), Vol 2,Issue 6,June 2014

[2] Eshaan Ayyar,Isacc de Souza, Aditya Parvin, Sanket Tambe, Aqleem Siddiqui and Nitin Gurav," Selection, Modification and Analysis of Suspension System for an All Terrain Vehicle", Int.J.on Theoretical and Applied Research in Mechanical Engineering, Vol-2, Issue -4 2013.

[3] Sarvadnya A. Thakare, Prasad C. Antapurkar,D.S.Shah, P.R.Dhamangaonkar and S.N.Sapali, "Design and analysis of Modified Front Double Wishbone Suspension for a Three Wheel Hybrid Vehicle.", World Congress on Engineering Vol II, July 2015.

[4] C.M.Choudhari..(2011,Jan) "Finite Element Analysis and testing of suspension arm.", National conference on advance in Mechanical engineering 2011.

[5] Vinayak Kulkarni and Anil Jadhav (2014,May) "Finite Element Analysis and Topology Optimization of Lower Arm of Double Wishbone Suspension using RADIOSS and Optistruct”, Int. J. of science and Research. Vol 3 Issue 5.

[6] A.M.Patil, A.S.Todkar, R.S.Mithari and V.V.Patil "Experimental and Finite Element Analysis of Left Side Lower Wishbone Arm of Independent Suspension System",IOSR Journal of Mechanical and Civil Engineering. Vol 7,Issue 2, pp 43-48, May-June 2013.

[7] Aniket Thosar,'Design, analysis and Fabrication of Rear Suspension System for an all Terrain Vehicle.", Int.J.of scientific and engineering research, Vol.5, Issue 11,Nov-2014.

[8] Ammar Qamar U1 Hasan "Simulation of ATV Roll Cage Testing”(Department of Mechanical Engineering, DIT University, India) IOSR Journal of Mechanical and Civil Engineering (IOSR-JMCE) e-ISSN: 2278-1684,p-ISSN: 2320-334X, Volume 12, Issue 3 Ver. II (May. - Jun. 2015), PP 45-49. 